\section{Depuración de Aguas Residuales y uso De Aguas Regeneradas: Un Análisis Descriptivo del Caso de la Provincia de Jaén}

\section{Wastewater Treatment and Use of Reclaimed Water: A Descriptive Analysis of The Case of The Province of Jaén}

\section{Encarnación Moral Pajares}

Universidad de Jaén

Jaén, España

emoral@ujaen.es

iD https://orcid.org/0000-0003-4790-0623

\section{Leticia Gallego Valero}

Universidad de Jaén

Jaén, España

Igallego@ujaen.es

(iD https://orcid.org/0000-0002-2682-6834

\section{Francisco García Moral}

Universidad de Jaén

Jaén, España

fgm00030@red.ujaen.es

iD https://orcid.org/0000-0003-3128-1696

\section{Isabel M. Román Sánchez}

Universidad de Almería

Almería, España

iroman@ual.es

(iD https://orcid.org/0000-0002-0098-4789

\section{Información del artículo:}

Recibido: 7 octubre 2019

Revisado: 13 diciembre 2019

Aceptado: 27 marzo 2020

$\begin{array}{ll}\text { ISSN } & 2340-8472 \\ \text { ISSNe } & 2340-7743 \\ \text { DOI } & 10.17561 / \text { AT.17.4988 }\end{array}$

\section{RESUMEN}

En 1991 se aprueba la Directiva 91/271/CEE que exige que las aguas residuales urbanas de los países de la UE sean tratadas antes de ser vertidas, favoreciendo su reutilización. El análisis exploratorio realizado permite afirmar que veintiséis años después de la aprobación de esta norma continúan existiendo municipios en Europa que no tratan las aguas servidas o lo hacen de forma incorrecta. Una realidad que influye negativamente en el estado ecológico y químico de los recursos hídricos, los ecosistemas naturales y la biodiversidad. Jaén, una provincia del sur de España, con 64 centros urbanos obligados a depurar las aguas vertidas, presenta en 2017 un elevado déficit en capacidad de tratamiento, siendo prácticamente nulo el volumen de agua reutilizada. Una situación que influye sobre las condiciones del medio natural hídrico.

PALABRAS CLAVE: Agua residual, Reutilización, Tratamientos, Unión Europea, Jaén.

\begin{abstract}
In 1991, Directive 91/271/EEC was approved, requiring that urban wastewater from EU countries be treated before being discharged, favoring its reuse. The exploratory analysis carried out allows us to affirm there are municipalities in Europe that do not treat sewage or do it incorrectly twentysix years after the approval of this norm. A reality that negatively influences the ecological and chemical state of water resources, natural ecosystems and biodiversity. Jaen, a province in southern Spain, with 64 urban centers forced to purify sewage, presents a high deficit in the purification capacity in 2017, with the volume of reused water being practically null. A situation that influences the conditions of the natural hydrological environment of the province.
\end{abstract}

KEYWORDS: Wastewater, Reuse, Treatment, European Union, Jaen

(c) CC-BY-SA

(c) Universidad de Jaén (España). 
Tratamento de águas residuais e uso de água regenerada: uma análise descritiva do caso da província de Jaén

\section{SUMÁRIO}

Em 1991, a Diretiva 91/271/CEE foi aprovada, exigindo que as águas residuais urbanas dos países da UE fossem tratadas antes de serem descarregadas, incentivando assim sua reutilização. A análise exploratória realizada nos permite afirmar que vinte e seis anos após a aprovação desta norma, ainda existem municípios na Europa que não tratam suas águas residuais ou o fazem de forma incorreta. Esta realidade tem uma influência negativa sobre o estado ecológico e químico dos recursos hídricos, dos ecossistemas naturais e da biodiversidade. Jaén, uma província do sul da Espanha, com 64 centros urbanos obrigados a tratar suas águas residuais, apresenta um alto déficit na capacidade de tratamento em 2017, com praticamente nenhuma água sendo reutilizada. Uma situação que influencia as condições do ambiente natural da água.

PALAVRAS-CHAVE: Águas residuais, Reutilização, Tratamentos, União Européia, Jaén.

Traitement des eaux usées et utilisation des eaux régénérées : analyse descriptive du cas de la province de Jaén

\section{RÉSUMÉ}

En 1991, la directive 91/271/CEE a été approuvée, exigeant que les eaux urbaines résiduaires des pays de l'UE soient traitées avant d'être rejetées, ce qui encourage leur réutilisation. L'analyse exploratoire effectuée nous permet d'affirmer que vingt-six ans après l'approbation de cette norme, il y a encore des municipalités en Europe qui ne traitent pas leurs eaux usées ou qui le font incorrectement. Cette réalité a une influence négative sur l'état écologique et chimique des ressources en eau, des écosystèmes naturels et de la biodiversité. Jaén, une province du sud de l'Espagne, avec 64 centres urbains obligés de traiter leurs eaux usées, présente un déficit important de capacité de traitement en 2017, avec pratiquement aucune réutilisation de l'eau. Une situation qui influence les conditions de l'environnement naturel de l'eau.

MOTS-CLÉS: Eaux usées, Réutilisation, Traitements, Union européenne, Jaén.
Trattamento delle acque reflue e utilizzo delle acque rigenerate: un'analisi descrittiva del caso della provincia di Jaén

\section{SOMMARIO}

Nel 1991 è stata approvata la direttiva 91/271/CEE, che impone di trattare le acque reflue urbane dei paesi dell'UE prima di essere scaricate, incoraggiandone così il riutilizzo. L'analisi esplorativa effettuata ci permette di affermare che ventisei anni dopo l'approvazione di questa norma, ci sono ancora comuni in Europa che non trattano le loro acque reflue o lo fanno in modo non corretto. Questa realtà ha un'influenza negativa sullo stato ecologico e chimico delle risorse idriche, degli ecosistemi naturali e della biodiversità. Jaén, una provincia nel sud della Spagna, con 64 centri urbani obbligati a trattare le loro acque reflue, presenta un alto deficit di capacità di trattamento nel 2017, con praticamente nessun riutilizzo dell'acqua. Una situazione che influenza le condizioni dell'ambiente naturale dell'acqua.

PAROLE CHIAVE: Acque reflue, Riutilizzo, Trattamenti, Unione Europea, Jaén. 


\section{Introducción ${ }^{1}$}

La importancia del agua para el desarrollo de la sociedad, el medio ambiente y la economía justifica que en 2010 la ONU reconociera como derecho humano el derecho al agua y al saneamiento. Posteriormente, en 2015, la Asamblea General de la ONU contempla el derecho a "un saneamiento que sea saludable, higiénico, seguro, social, culturalmente aceptable, que garantice la intimidad y la dignidad, considerando la premisa "agua limpia y saneamiento" como uno de los 17 objetivos globales de la Agenda para el desarrollo sostenible 2030, aprobada el 25 de septiembre de 2015. Concretamente, la meta 6.3 de dicha Agenda establece: "Mejorar la calidad del agua mediante la reducción de la contaminación, la eliminación del vertimiento y la reducción al mínimo de la descarga de materiales y productos químicos peligrosos, la reducción a la mitad del porcentaje de aguas residuales sin tratar y un aumento sustancial del reciclado y la reutilización en condiciones de seguridad a nivel mundial". La adecuada gestión de este recurso también se encuentra incluido en el objetivo 15 (acción sobre el clima, eficiencia, recursos y materias primas) de la Estrategia Española de Ciencia y Tecnología de la Innovación 2020, y coincide con la política de la Unión Europea para garantizar la sostenibilidad de las aguas comunitarias, concretada en la Directiva 91/271/CEE y, posteriormente, la Directiva Marco del Agua 2000/60/CE. En esta línea se incluye, además, la propuesta de la OCDE en el marco de las Perspectivas Ambientales para el 2050, entre las que se considera la necesidad de protección de los medios hídricos.

Las crecientes exigencias sanitarias y ambientales sobre la calidad de las aguas continentales y marinas y los estrictos niveles de tratamiento impuestos a los vertidos de aguas residuales han propiciado que los recursos hídricos regenerados se configuren en una opción adecuada para incrementar la oferta disponible ${ }^{2}$. Paralelamente, la continua expansión de la demanda de agua, tanto por parte de la población como del sistema productivo, especialmente la agricultura, a la que se destina el 70 por 100 del agua dulce extraída del

\footnotetext{
1. Este trabajo presenta parte de los resultados de investigación de un proyecto de investigación financiado por el Instituto de Estudios Giennenses, en la convocatoria 2017, con el título: "Análisis económico del sistema de gestión de vertidos de aguas residuales urbanas en la provincia de Jaén y valoración de su capacidad para obtener agua regenerada para el riego". Los autores agradecen muy sinceramente las recomendaciones y comentarios de los revisores, que han contribuido a la mejora de este trabajo.

2. Hochstrat et al., 2010. García y Pargament, 2015. Wilcox et al. 2016.
}

planeta $^{3}$, la sequía, el agotamiento y la dependencia de fuentes únicas de suministro han provocado que comunidades de todo el mundo se enfrenten a problemas de abastecimiento ${ }^{4}$. Ante esta realidad, los procesos de reutilización de agua residual se configuran como una herramienta fundamental para conseguir que aumente el recurso disponible, como una fuente alternativa de abastecimiento, económica y segura desde el punto de vista sanitario y ambiental ${ }^{5}$, que permite una menor dependencia de las fuentes subterráneas y superficiales ${ }^{6}$. La regeneración y reutilización de los efluentes vertidos es ya una práctica habitual implementada en países como Francia, Italia, Chipre, Malta, Israel, Jordania o Estados Unidos; siendo su destino principal el riego de jardines $y$, sobre todo, la agricultura ${ }^{7}$. En este sentido, conviene mencionar el proyecto SUWANU EUROPE $^{8}$ desarrollado desde la UE y que tiene como propósito impulsar el uso de aguas regeneradas en la agricultura.

El objetivo de esta investigación es conocer la situación que presenta el sistema de gestión de las aguas residuales en Jaén, una provincia del sur de España de marcada especialización oleícola ${ }^{9}$, y analizar cómo los efluentes hídricos depurados se emplean para el regadío agrícola. Los trabajos sobre los distintos aspectos de la gestión del agua en esta provincia son escasos, pudiéndose destacar el desarrollado a nivel local por el Ayuntamiento de Jaén en 2013, el publicado por la Diputación Provincial en 2003, con el título: "Ciclo integral del agua. Abastecimiento, tratamiento y distribución de agua potable; consumo de agua potable; red de alcantarillado y depuración de aguas", los de carácter sectorial de Araque, Gallego y Sánchez (2002) y Sánchez, Gallego y Araque (2011) sobre el olivar de regadío en la provincia de Jaén, el de Berbel y Expósito (2006) que trata sobre costes del servicio de abastecimiento urbano en la demarcación del Guadalquivir y el de Expósito y Berbel (2017) sobre ineficacia de precios del agua para riego. Son inexistentes, sin embargo, aquellos cuyo objeto de investigación es el análisis y estudio de los sistemas de gestión de las aguas residuales vertidas y su regeneración.

\footnotetext{
3. Winpenny et a., 2013.

4. Miller, 2006.

5. Melgarejo, 2009. Lazarova et al., 2001.

6. Ruiz-Rosa, García-Rodríguez y Mendoza-Jiménez, 2016. Gharbia et al., 2016.

7. Kalavrouziotis et al., 2013. Pedrero et al., 2010. Melian-Navarro y Fernández-Zamudio, 2016.

8. Se puede consultar en https://suwanu-europe.eu/water-reuse-projects -europe/

9. Sánchez y Ortega, 2016.
} 
El contenido de este trabajo se estructura en cinco aparados, incluido este de carácter introductorio. En el siguiente se analizan los compromisos de las corporaciones locales españolas en materia de depuración de aguas residuales urbana, de acuerdo con la normativa de la UE. En el tercer apartado se valora el grado de ejecución y cumplimiento de las obligaciones que establece la Directiva 91/271/CEE sobre tratamiento de aguas residuales urbanas (ARU) en la provincia de Jaén. Posteriormente, se evalúa el uso de aguas residuales tratadas para el riego en el territorio provincial. Finalmente, en el quinto apartado, se recogen las conclusiones y las principales reflexiones que se derivan del estudio.

\section{Política ambiental y depuración de aguas residuales en la UE}

La política ambiental de la UE incluye entre sus objetivos fundamentales la conservación, protección y mejora de la calidad del agua, así como la utilización prudente y racional de los recursos naturales (Artículo 130R del Tratado de la Unión Europea). La mejora de la calidad de los recursos hídricos ha de hacerse compatible, además, con un aumento sustancial del reciclado y la reutilización, que garantice un incremento de la disponibilidad $^{10}$.

El 21 de mayo de 1991 se adopta en la UE la Directiva 91/271/CEE, sobre tratamiento de las aguas residuales urbanas, que establece las medidas necesarias que los Estados miembros han de adoptar para garantizar que los efluentes urbanos ${ }^{11}$, reciban un tratamiento adecuado antes de su vertido a las aguas continentales o marinas ${ }^{12}$, exigiendo la aplicación de procesos más rigurosos (para una mayor eliminación de nitrógeno y potasio), con el propósito de reducir los niveles de contaminación de las aguas superficiales que provienen de una aglomeración urbana y situadas en las zonas sensibles designadas.

La transposición de la Directiva 91/271/CEE al Derecho español se realiza a través del Real Decreto-Ley 11/1995, por el que se establecen las normas aplicables al tratamiento de las aguas residuales urbanas. En este RD-Ley se fijan los plazos para que empiecen a

\footnotetext{
10. Collins et al., 2009. Molinos-Senante, Hernández-Sancho y Sala-Garrido, 2010. Schewe et al., 2014. Pedro-Monzonís et al., 2015.

11. Según el art. 2.1, D. 91/271/CEE, se consideran como tales las aguas residuales domésticas o la mezcla de las mismas con aguas residuales industriales y/o aguas de escorrentía pluvial.

12. Gallego-Valero et. al, 2018.
}

funcionar sistemas colectores y de depuración. Por su parte, el Real Decreto 509/1996 desarrolla el contenido del anteriormente citado, mediante la incorporación de los Anexos incluidos en la Directiva 91/271/CEE, que no habían sido incorporados inicialmente, y contiene los valores que deben cumplir los vertidos a la salida de la Estación Depuradora de Aguas Residuales (EDAR), el criterio de conformidad y los criterios para declarar zonas sensibles.

En octubre de 2000 se aprueba la Directiva 2000/60/ CE (DMA), estableciendo un marco comunitario de actuación en el ámbito de la política de aguas, con el propósito de garantizar un buen estado ecológico y químico de los recursos hídricos, para proteger la salud humana, el suministro, los ecosistemas naturales y la biodiversidad. Esta norma supuso un gran impulso a las prácticas de gestión y a las políticas europeas en materia de aguas, incidiendo, particularmente, en los aspectos medioambientales, por encima de los demás, estableciendo una legislación común y un marco comunitario de actuación con el propósito de detener el deterioro de las masas de agua en los países de la zona y conseguir un "buen estado" de los ríos, lagos y las aguas subterráneas europeas en 2015. Concretamente, pretendía la reducción de los niveles de contaminación, la protección de todas las formas de agua (superficiales, subterráneas, continentales y de transición) y la regeneración de los ecosistemas de dentro de estas masas de agua y en su entorno, bajo la premisa principal de "quien contamina, paga" recogida en el art. 9 de la DMA. En España, la trasposición de la Directiva 2000/60/CE se realiza mediante la Ley 62/2003, de 30 de diciembre, de medidas fiscales, administrativas y del orden social que incluye, en su artículo 129, la modificación del texto refundido de la Ley de Aguas, aprobado por Real Decreto Legislativo 1/2001, de 20 de julio.

En el ámbito local, art. 25.2 c) de la Ley de las Bases de Régimen Local 7/1985, de 2 de abril, atribuye a todos los municipios competencias en materia de abastecimiento de agua potable a domicilio y evacuación y tratamiento de aguas residuales. Por su parte, la Ley 5/2010, de 11 de junio, de Autonomía Local de Andalucía, en su art. 9 dedicado a las competencias municipales, determina que los municipios andaluces tienen como competencias propias la ordenación, gestión, prestación y control de los diferentes servicios en el ciclo integral del agua de uso urbano, entre los que se incluyen el saneamiento o recogida de aguas residuales urbanas y la depuración de éstas. De las normas antes expuestas resulta clara la responsabilidad y el deber de 
las corporaciones locales en relación al saneamiento, que incluye el alcantarillado (o recogida) y la depuración de las aguas residuales, para garantizar la calidad del medio ambiente.

\section{Recogida y tratamiento de aguas residuales urbanas}

Corresponde, en este apartado, realizar un análisis comparado de la situación que presenta la provincia de Jaén en relación al cumplimiento de los requisitos que establece la Directiva 91/271/CEE (Directiva ARU), tanto en lo relativo al establecimiento de sistemas de colectores (art. 3) como en cuanto a disponer de EDAR de tratamientos secundarios, en función del tamaño de las aglomeraciones de las que proceden (art. 4). Para ello, se utiliza principalmente la última información disponible, reportada por los Estados miembros de la UE a la Comisión, recopilada de enero a diciembre de 2014, con arreglo a los requisitos que establecen los artículos 15 y 17 de la Directiva ARU ${ }^{13}$.

\section{SisTEMAS DE COLECTORES}

La red de colectores de un centro urbano está conformada por un conjunto de tuberías que recoge las aguas servidas y pluviales y las transporta desde el alcantarillado municipal hasta la estación depuradora. Dependiendo de la topografía, las aguas discurrirán por gravedad o será necesario recurrir a su bombeo. En la provincia jiennense, los sistemas de recogida son unitarios y, por tanto, la red de saneamiento agrupa las aguas residuales y las de lluvia. En otros casos, los colectores que llegan a la estación de tratamiento transportan tan sólo aguas residuales, mientras que las aguas de lluvia se acumulan en colectores independientes (sistemas separativos). Con el objetivo de que a la estación depuradora no llegue más caudal del proyectado, en los colectores y/o en las obras de llegada a las EDAR, se instalan tanques de tormenta, que permiten derivar los excesos de caudal. Esta situación tiene lugar principalmente en períodos en los que se registran fuertes lluvias ${ }^{14}$.

Para cumplir con la Directiva ARU, los Estados miembros habrían de velar porque las aglomeraciones

\footnotetext{
13. En 2014, Croacia no tiene obligación de cumplimiento y no reporta datos (Comisión Europea, 2017b).

14. Alianza por el Agua, 2003.
}

urbanas cuenten con colectores, en las siguientes circunstancias:

- a más tardar, el 31 de diciembre del año 2000 en el caso de las aglomeraciones con una carga contaminante de más de $15.000 \mathrm{~h}-\mathrm{e}^{15} \mathrm{y}$

- a más tardar, el 31 de diciembre del año 2005 en el caso de las aglomeraciones con un vertido entre 2.000 y 15.000 h-e.

Cuando se trate de aguas residuales urbanas vertidas en aguas receptoras que se consideren "zonas sensibles" con arreglo a la definición del art. 5, los Estados miembros velarán por que se instalen sistemas colectores, a más tardar, el 31 de diciembre de 1998 en las aglomeraciones con más de 10.000 h-e.

El noveno informe sobre el estado de ejecución y los programas de aplicación de la Directiva 91/271/CEE ${ }^{16}$ concluye que el grado de cumplimiento en el conjunto de la UE es elevado, con un valor medio del 94,7 por 100, tal y como refleja Gráfico 1. Existen, sin embargo, diferencias importantes entre los Estados miembros.

En los últimos años, en general, los países han mantenido o mejorado sus índices de cumplimiento o conformidad, excepto Rumanía, Chipre y España, que en 2014 presenta un valor del 97 por 100, ligeramente superior a la media de la zona. En Austria, Bélgica, Chequia, Dinamarca, Finlandia, Francia, Alemania, Grecia, Hungría Irlanda, Letonia, Lituania, Luxemburgo, Malta, Países Bajos, Portugal, Eslovaquia, Suecia y Reino Unido el grado de cumplimiento es de un 100 por 100. Frente a estos resultados tres países figuran con índices bajos, inferiores al 70 por 100 (Bulgaria, Eslovenia y Chipre).

La Agencia Europea del Medio Ambiente ${ }^{17}$ ofrece información sobre la situación de las 17 Comunidades Autónomas más las Ciudades Autónomas de Ceuta y Melilla a finales del año 2014, en cuanto a disponer de colectores para la recogida de aguas residuales. Andalucía con un índice de cumplimiento del 99 por 100, mantiene una posición ligeramente superior a la media nacional, muy alejada de Asturias, la Comunidad que ostenta la peor posición relativa en el contexto

\footnotetext{
15. Habitantes equivalentes (h-e) es una unidad de contaminación de las aguas vertidas, considerando tanto las domésticas, según la población del núcleo urbano, como las que proceden de las diferentes actividades económicas que se desarrollan en el municipio (industria, ganadería, etc.). La Directiva 91/271/CEE establece que 1 h-e tiene una carga orgánica biodegradable con una demanda bioquímica de oxígeno de cinco días (DB05) equivalente a 60 gramos de oxígeno día.

16. Comisión Europea, 2017b.

17. EEA, 2017
} 
Gráfico 1. Grado de cumplimiento del art. 3 de la Directiva ARU en los países de la UE (en \%)

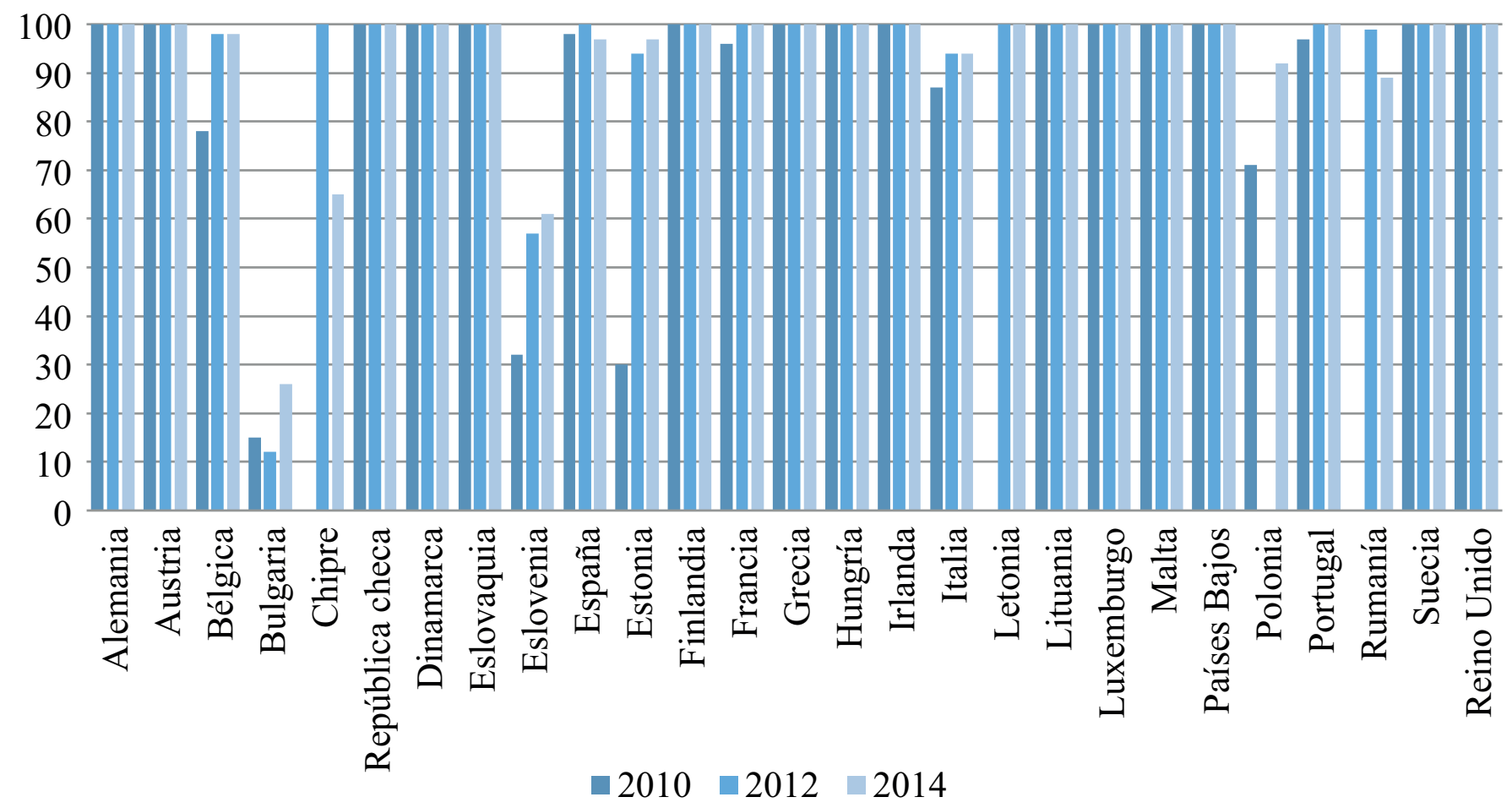

Fuente: EEA (2017).

nacional, que presenta un índice de cumplimiento del 58 por 100 y más de una docena de no conformidades, le sigue Islas Canarias (62 por 100), Cantabria (94 por 100) e Islas Baleares (97 por 100).

Catorce regiones figuran con una situación óptima, cumpliendo totalmente con los requisitos exigidos en la Directiva ARU, contando con una cobertura total de la red de alcantarillado de los municipios de su región. Ésta debe recoger y conducir rápidamente hasta el sistema de colectores, sin estancamientos ni fugas, tanto las aguas pluviales como las residuales domésticas o industriales ${ }^{18}$, evitando que cualquier tipo de producto vertido a la red contamine durante su trayecto o al término del mismo, tanto a las aguas subterráneas como las superficiales. Los colectores evitan que las aguas servidas vayan a parar a las masas de agua y garantizan que estas lleguen a las depuradoras.

En Andalucía, los datos de la EEA para 2014 constatan un alto nivel de cumplimiento. Seis provincias, entre las que se incluye la jiennense, registran un índice del 100 por 100, Almería no llega al 98 por 100, siendo Granada la que figura en última posición, con un 96 por 100.

En la provincia de Jaén, con un total de 97 municipios (ver Mapa 1), once de ellos (Alcalá la Real, Andújar,

\footnotetext{
18. Las aguas pluviales y residuales se pueden canalizar por el mismo conducto (caso de redes unitarias, mayoritarias en España ya que suponen un 75 por 100 de la longitud) o por diferentes conductos (redes separativas) (AEAS, 2017).
}

Martos, Úbeda, La Carolina, Jaén, Linares, Villacarrillo, Torredelcampo, Bailen y Jódar) son los catalogados con más de 15.000 h-e, debiendo cumplir con las instalaciones adecuadas para la recogida de aguas residuales en el año 2000, siendo 53 los obligados a disponer de dichas instalaciones en 2005. En 2014, la provincia presenta una realidad conforme al 100 por 100 a la norma comunitaria. No obstante, seguían pendientes de estar completados tres colectores (Carchelles- Carchelejo, La Carolina y el de Puente Génave-La Puerta de Segura).

\section{DePuRACión de AGUAS RESIDUALES}

El art. 4 de la Directiva ARU establece que los Estados miembros velarán para que las aguas residuales urbanas que entren en los sistemas colectores sean objeto, antes de verterse, de un tratamiento secundario o de un proceso equivalente, en las siguientes circunstancias:

- a más tardar el 31 de diciembre del año 2000 para todos los vertidos que procedan de aglomeraciones que representen una carga de más de $15.000 \mathrm{~h}-\mathrm{e}$;

- a más tardar el 31 de diciembre del año 2005 para todos los vertidos que procedan de aglomeraciones que representen una carga de entre 10.000 y 15.000 h-e; 


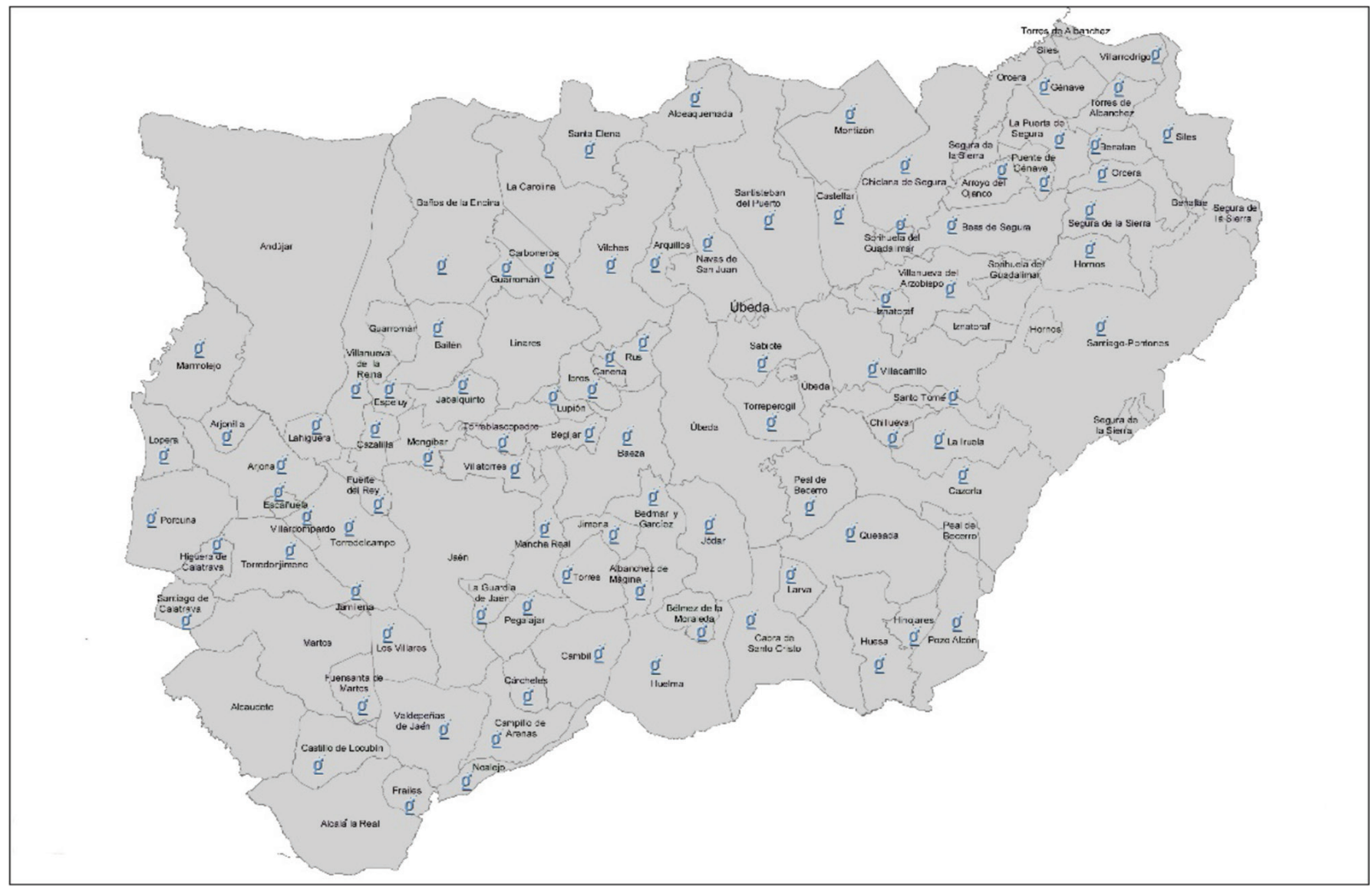

Fuente: Diputación de Jaén.

- a más tardar el 31 de diciembre del año 2005 para los vertidos en aguas dulces o estuarios que procedan de aglomeraciones que representen una carga de entre 2.000 y 10.000 h-e.

El punto 8 del art. 2 de esta Directiva define el tratamiento secundario de una EDAR como aquél proceso que incluye, por lo general, un tratamiento biológico con sedimentación secundaria, $u$ otro en el que se respeten los requisitos que se establecen en el Anexo I de la Directiva, en relación a $\mathrm{DBO}_{5}$, DQO y Sólidos en Suspensión, y considerando los métodos de seguimiento y evaluación especificados.

A finales de 2014, en la UE se tratan correctamente, con tratamiento secundario, un 88,7 por 100 de las aguas residuales vertidas, según la Comisión Europea. Los datos representados en el Gráfico 2 permiten advertir importantes diferencias entre los países de la zona, que identifican un desigual nivel de compromiso con el control de los vertidos urbanos y, asimismo, con el objetivo de mantener un buen estado ecológico de las aguas.
Los Estados que cumplen totalmente con el art. 4, son Austria, Dinamarca, Alemania, Letonia, Lituania, Luxemburgo y Países Bajos. Con un índice del 95 por 100 o más figuran 7 economías nacionales (Bélgica, Finlandia, Grecia, Hungría, Eslovaquia, Suecia y Reino Unido). Entre un 85 y un 94 por 100, presentan Chipre, República checa, Estonia, Francia y Polonia. España, con un índice del 84 por 100, se sitúa por encima de los países más rezagados del grupo, como son Bulgaria, Irlanda, Italia, Portugal, Rumanía y Eslovenia.

En 2014, considerando los centros urbanos con más de 2.000 h-e, España cuenta una capacidad de depuración de 2.286.260.221 h-e/año, y un volumen de carga tratada de 60.488.649,21 h-e/año, lo que determina un exceso de capacidad que, sin embargo, no responde a la realidad que ofrecen determinados territorios, como es el caso de Siles, en la provincia de Jaén, con un ratio de explotación del 134 por $100^{19}$, Albarracín, en la Teruel, con un del 221 por 100, Siruela en Badajoz con un 268 por 100 o San Roque, en Cádiz, con un 510 por 100.

\footnotetext{
19. Siles es el único municipio de la provincia con una ratio superior al 100 por 100
} 
Gráfico 2. Cumplimiento del art. 4 de la Directiva ARU en los países de la UE en 2014 (en \%)

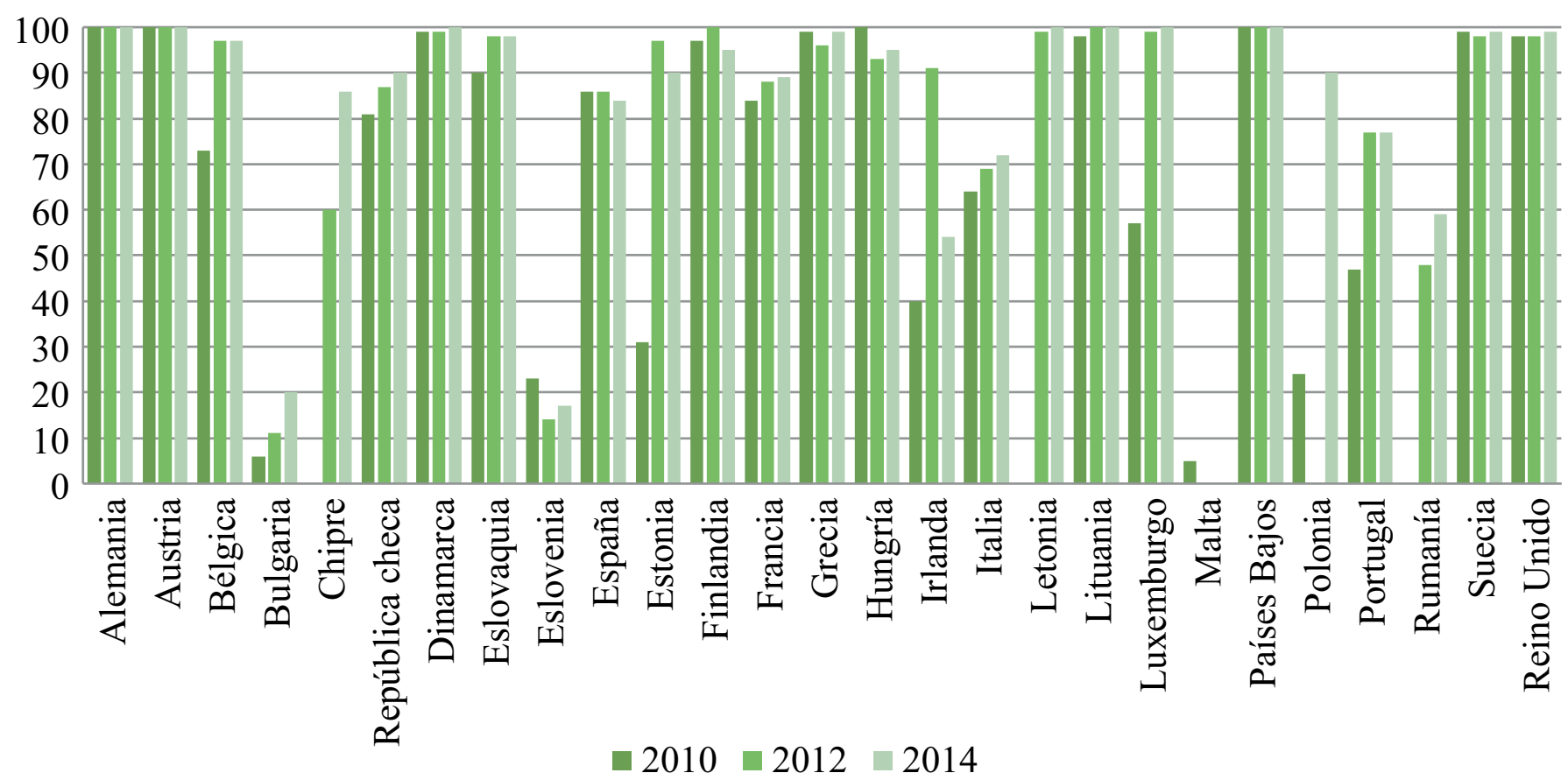

Fuente: EEA (2017).

Entre las distintas Comunidades Autónomas la situación es muy dispar, siendo una minoría las que consiguen tratar adecuadamente el 100 por 100 de sus vertidos (Gráfico 3). Es el caso de Ceuta y Melilla, La Rioja, Navarra y Murcia, responsables del 7 por 100 del total de efluentes que se generan en el conjunto de la nación. En la posición opuesta se encuentran Asturias, que sólo gestiona correctamente un 45 por 100, e Islas Canarias con un 62 por 100. Presentan un porcentaje superior al 90 por 100, Cataluña (99 por 100), Comunidad Valenciana (98 por 100) y Aragón (91 por 100). Alejada de estos resultados se sitúa Andalucía, en la que se genera el 18 por 100 de todas las aguas servidas del conjunto de España, presentando un índice de cumplimiento de 79 por 100.

En el contexto regional, la provincia jiennense es la que registra una peor posición relativa en 2014, con valores muy alejados de los imputables al conjunto del Estado y la región. Del total de aguas vertidas en municipios con una carga de más de 2.000 h-e, las que son procesadas adecuadamente no llega al 60 por 100 , tal y como constata la información del Mapa 2. Una realidad que responde a la reducida capacidad de depuración instalada en el territorio y, asimismo, al elevado número de estaciones depuradoras que no funcionan conforme a la norma. Frente a esta situación, dos provincias andaluzas, Almería y Sevilla, gestionan satisfactoriamente un 88 por 100 y, otras dos, Málaga y Córdoba, más del 80 por 100 .

Para conocer lo que ocurre en los municipios jiennense, en el Gráfico 4 se recoge información sobre el grado de cumplimiento del art. 4 de la Directiva ARU, para aquellos con un volumen de vertido igual o mayor a 2.000 h-e, en diciembre de 2014 y 2017. Destaca, ante todo, que son mayoría los que incumplen los compromisos que en materia de gestión de las aguas vertidas establece la norma de la UE. De hecho, sólo 23 son los que en 2017 operan conforme a lo que establece el Anexo 1 de la Directiva 91/271/CEEE, presentando un rendimiento medio de reducción del $\mathrm{DBO}_{5}$ del 82,50 por 100 , del DQO del 88,29 por 100 y de Sólidos en Suspensión del 87,51 por 100 .

Entre las estaciones depuradoras que están operativas en 2014 (Figura 1), 15 son las que lo hacen de forma correcta (Alcalá la Real, Andújar, Bailen, Baños de la Encina, Bedmar, Bélmez de la Moraleda, La Carolina, Jaén, Linares, Mancha Real, Marmolejo, Mengíbar, Peal de Becerro, Torreperogil y Los Villares). Por tanto, son mayoría las que presentaban ciertas limitaciones en el desarrollo de su actividad, lo que determina su no conformidad con los requisitos que establece la Directiva ARU. Esta situación mejora considerablemente en los últimos años, como evidencian los datos, dado que algunas depuradoras han pasado a ser conformes, como 
Gráfico 3. Cumplimiento del art. 4 de la Directiva ARU por Comunidades Autónomas en 2014 (en \%)

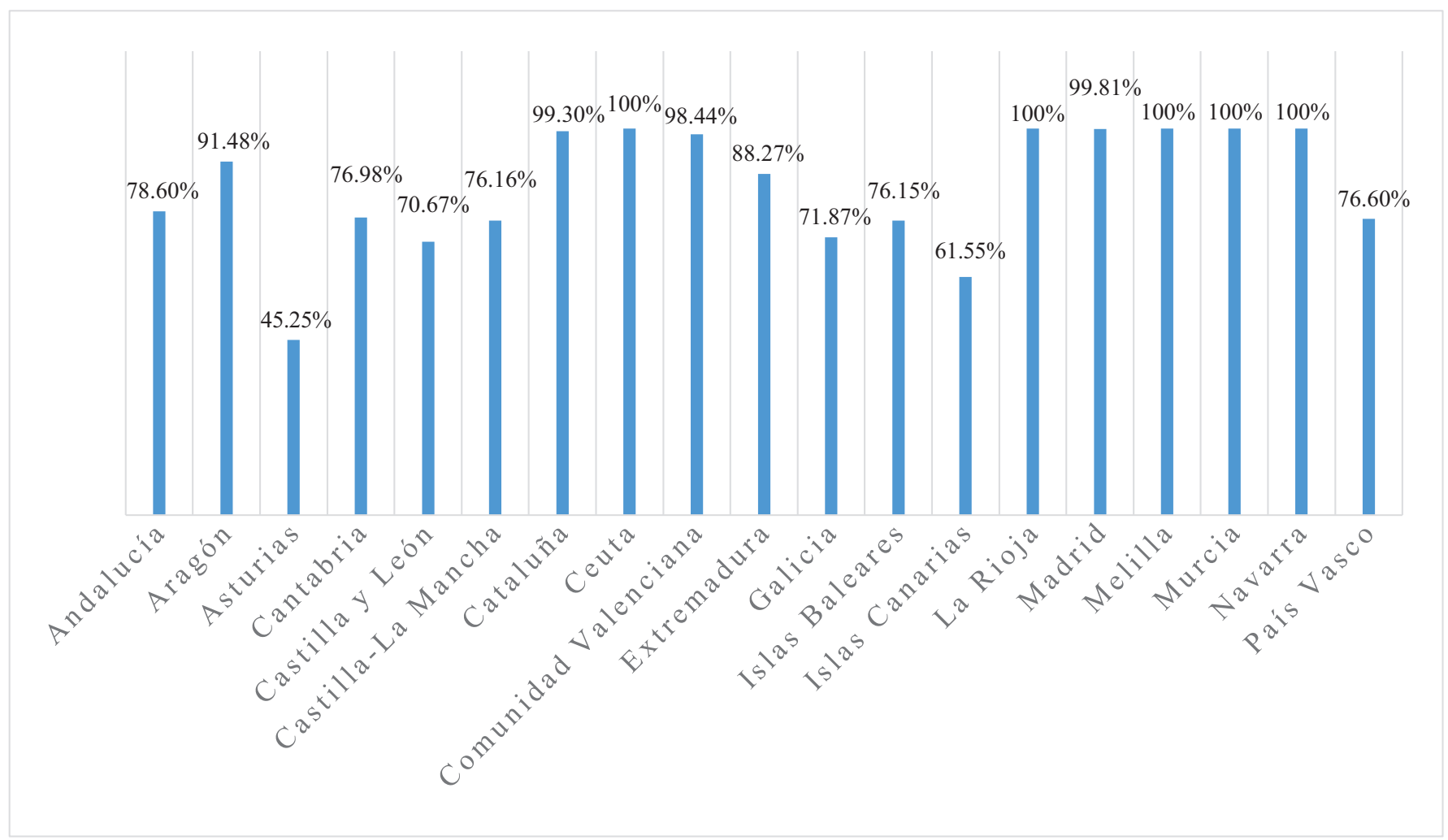

Fuente: EEA (2017).

Mapa 2. Grado de cumplimiento del art. 4 de la Directiva ARU en las provincias andaluzas en 2014 (en \%)

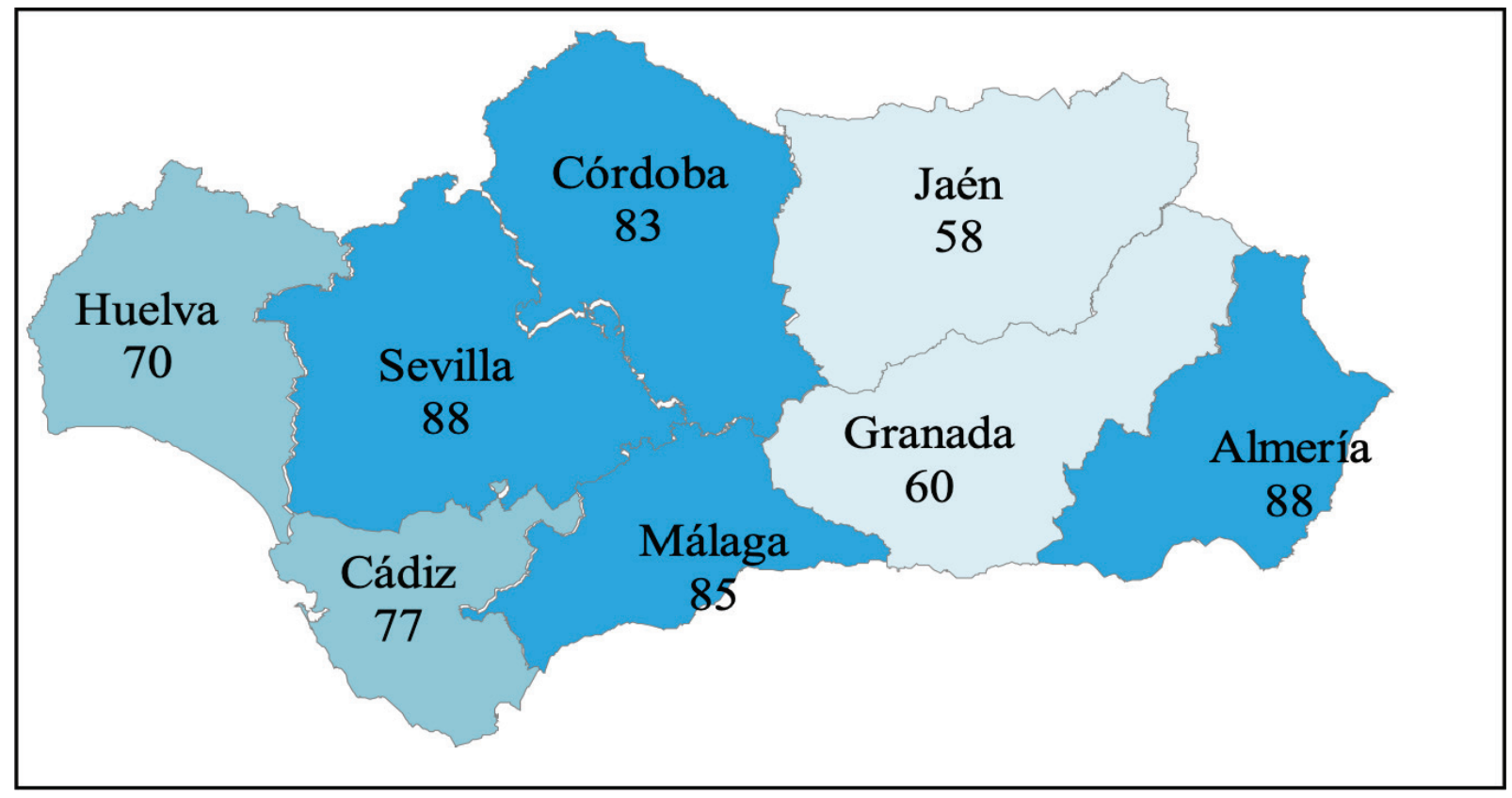

Fuente: EEA (2017).

ocurre con las de Alcaudete ${ }^{20}$, Baeza, Cazorla, Huelma, Quesada, Torredelcampo y Villacarrillo, lo que ha permitido aumentar en un 20,7 por 100 el volumen de vertidos tratados correctamente en cuatro ejercicios.

\footnotetext{
20. Según la EEA no contaba con EDAR en 2014.
}

Tanto en 2014 como en 2017 seis instalaciones figuran como paradas. En muchos de estos casos, se trata de infraestructuras prácticamente culminadas, pero en las que el proceso de puesta en marcha se ha retrasado, por múltiples motivos. Es lo acontecido en dos de los centros urbanos más grandes de la provincia, 
Gráfico 4. Grado de cumplimiento del art. 4 de la Directiva ARU en los municipios de la provincia de Jaén con más de 2.000 h-e en 2014 y 2017 (número de casos)

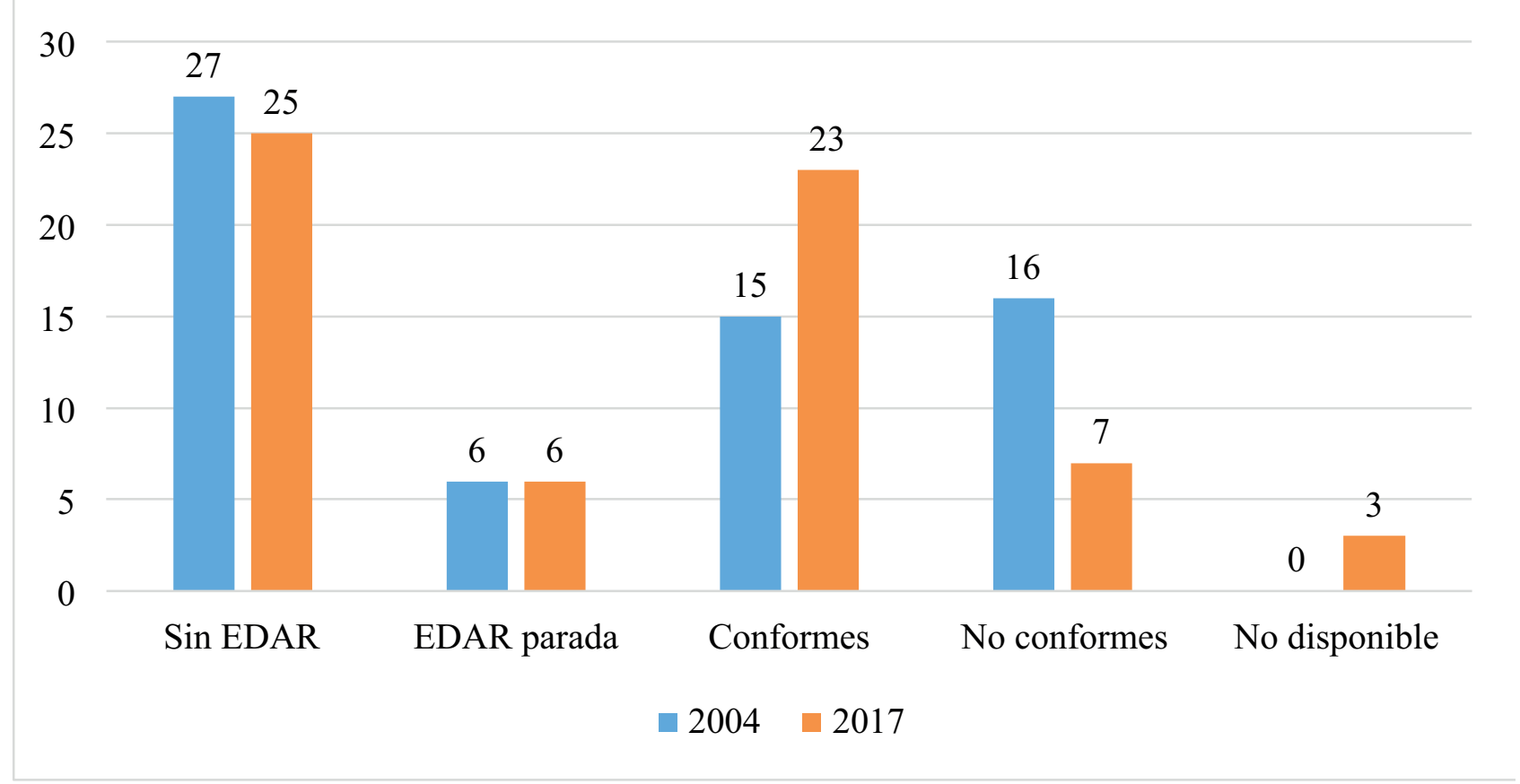

Fuente: EEA (2017) y Diputación provincial de Jaén (2003).

Figura 1. Depuradora de aguas residuales de Alcalá la Real

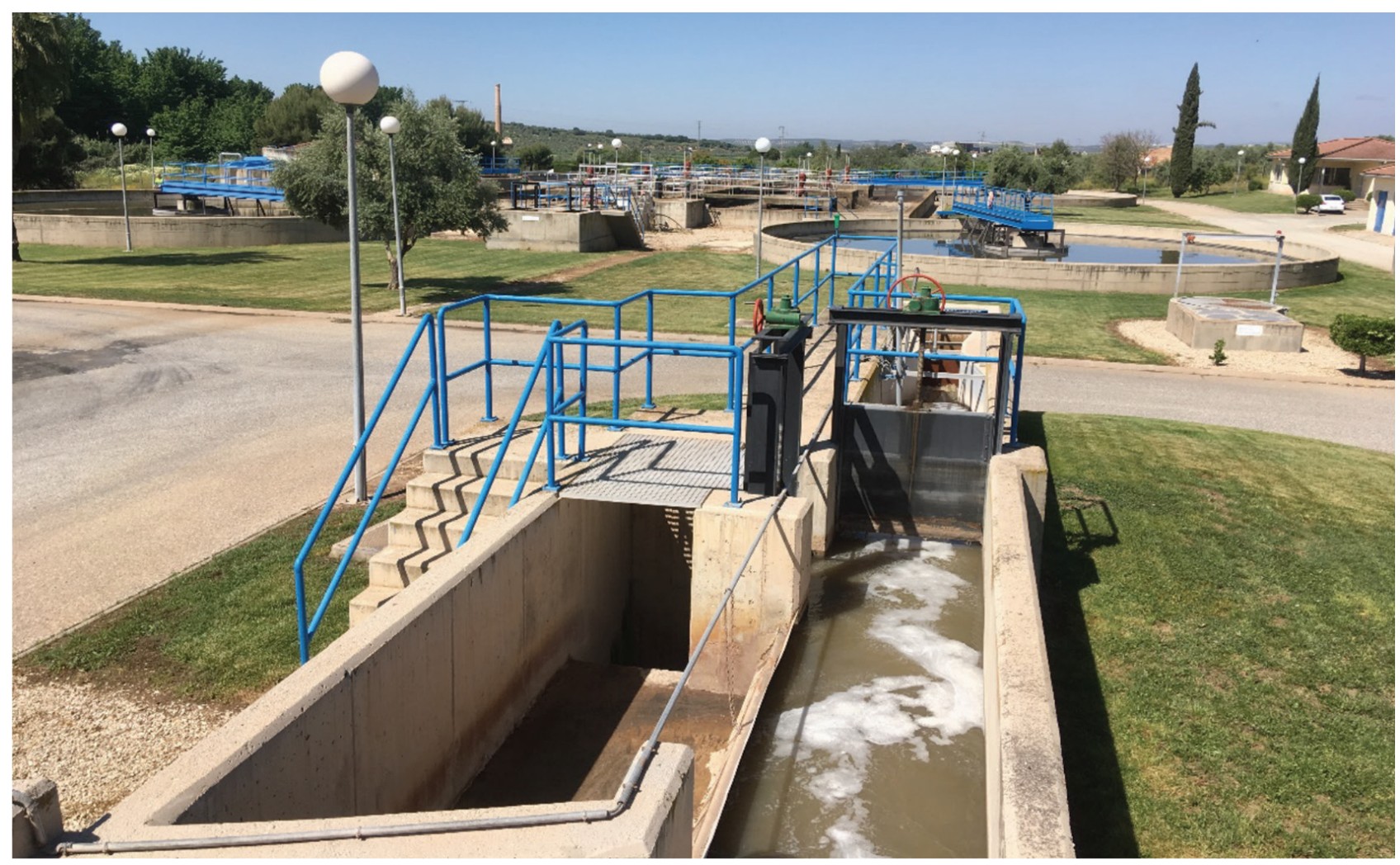

Fuente: Elaboración propia. 
Martos $^{21}$ y Úbeda, con una descarga generada de 31.383 y 54.944 h-e, respectivamente.

A finales de 2017, de las 64 depuradoras que debían estar operativas en los centros urbanos de la provincia, con una carga de vertido estimada igual o superior a 2.000 h-e, sólo lo hacen 33. La población servida por estas instalaciones asciende 428.007 habitantes, representando un 67 por 100 del total. El Gráfico 5 compara la carga generada en los municipios provinciales y la capacidad de depuración. Esta información y la del Gráfico 4 permiten afirmar que el territorio mantiene un importante déficit en capacidad de depuración, lo que influye negativamente en la calidad de los vertidos y repercute muy desfavorablemente en el medio ambiente. Una realidad que resulta especialmente significativa en tres centros urbanos con una carga contaminante superior a 15.000 h-e, que deberían estar depurando sus aguas residuales a partir del año 2000 y en 2018 no lo hacen, como es el caso de Úbeda, Martos y Torredonjimeno. Con una carga de menos de 10.000 h-e, se incluye un grupo 22 pueblos sin EDAR, en el que se encuentran Valdepeñas de Jaén, Campillo de Arenas, Santisteban del Puerto, Sabiote, Castillo de Locubín, Viches, Navas de Sam Juan o Arjona, que generan individualmente y cada año una carga mayor a 7.000 h-e.

\section{Reutilización de aguas residuales}

El riego con aguas residuales tratadas es una práctica común en los países mediterráneos ${ }^{22}$. España, el país más árido de la $\left.\mathrm{UE}^{23}\right)$, con un índice de estrés hídrico muy elevado ${ }^{24}$, registra en 2016 un volumen de agua tratada de $12,9 \mathrm{hm}^{3}$ / día, siendo $1,34 \mathrm{hm}^{3} /$ día, un 10,4 por 100, la cantidad reutilizada ${ }^{25}$. En el conjunto del Estado, un 61,2 por 100 del total de agua regenerada es usada en agricultura, según los últimos datos publicados por el $\mathrm{INE}^{26}$. En Andalucía, sin embargo, el porcentaje de reutilización se cifra en un 5,9 por 100 en 2016, siendo la industria y el riego de jardines y zonas deportivas de ocio destino prioritario para este recurso. La agricultura sólo recibe un escaso 2,5 por 100 del total de agua reutilizada en la región en 2016.

\footnotetext{
21. Las obras sufrieron un importante retraso debido a que se encontraron restos arqueológicos, por los que se paró la intervención.

22. Pedrero et al., 2010.

23. Llamas et al., 2009.

24. World Resources Institute, 2017.

25. Gallego Valero et. al. 2019

26. Indicadores sobre aguas residuales por Comunidades Autónomas.
}

El objetivo de este apartado es conocer el estado actual de las aguas residuales reutilizadas en la agricultura en la provincia de Jaén, un territorio que cuenta con 312.508 ha. de tierras de cultivo agrícola de regadío, según la Encuesta sobre Superficies y Rendimientos de Cultivos de 2018, del Ministerio de Agricultura, Pesca y Alimentación. Teniendo en cuenta que más del 95 por 100 de la superficie de la provincia jiennense se incluye en la demarcación geográfica del Guadalquivir y a partir de la información facilitada por la Confederación Hidrográfica de dicho río, se valora el uso de aguas residuales para riego por parte de la agricultura provincial.

El marco legal para la reutilización de aguas depuradas en España lo fija el Real Decreto 1620/2007, de 7 de diciembre de 2007, definiendo el concepto de reutilización y de agua regenerada, tratando los aspectos relativos al régimen jurídico de la concesión y/o autorización $\mathrm{y}$, asimismo, estableciendo las condiciones de calidad que debe cumplir el agua regenerada, sus usos permitidos y prohibidos y el régimen de responsabilidades en relación al mantenimiento de la calidad. En 2010, el Ministerio de Medio Ambiente y Medio Rural y Marino publica la Guía para la aplicación de este Real Decreto.

La reutilización de las aguas se define como la aplicación, antes de su devolución al dominio público hidráulico y al marítimo terrestre para un nuevo uso privativo de las aguas que, habiendo sido utilizadas por quien las derivó, se han sometido al proceso o procesos de depuración establecidos en la correspondiente autorización de vertido y a los necesarios para alcanzar la calidad requerida en función de los usos a que se van a destinar. Por tanto, para su consideración como recursos disponibles, los volúmenes regenerados deberán cumplir los parámetros de calidad requeridos para el uso expectante. Concretamente, los parámetros de calidad del agua regenerada exigida para poder ser empleada en el riego de cultivos leñosos, entre los que se incluye el olivar, son los que se detallan en el Cuadro 1.

La Memoria del PHDHG 2015-2021 resalta el hecho de que la cuenca presenta una tasa elevada de reutilización indirecta debido a su estructura en espina de pez, por lo que implícitamente se reutilizan los efluentes en usos aguas abajo. Por otra parte, se estima que entre el 0,5 y el 1 por 100 de los recursos hídricos destinados a la satisfacción de las demandas proceden de la reutilización directa. El Plan considera que las aguas reutilizadas no tienen la consideración de nuevo recurso, ya 
Gráfico 5. Carga generada y capacidad de depuración por grupos de municipios en la provincia de Jaén en 2017 (en m³)

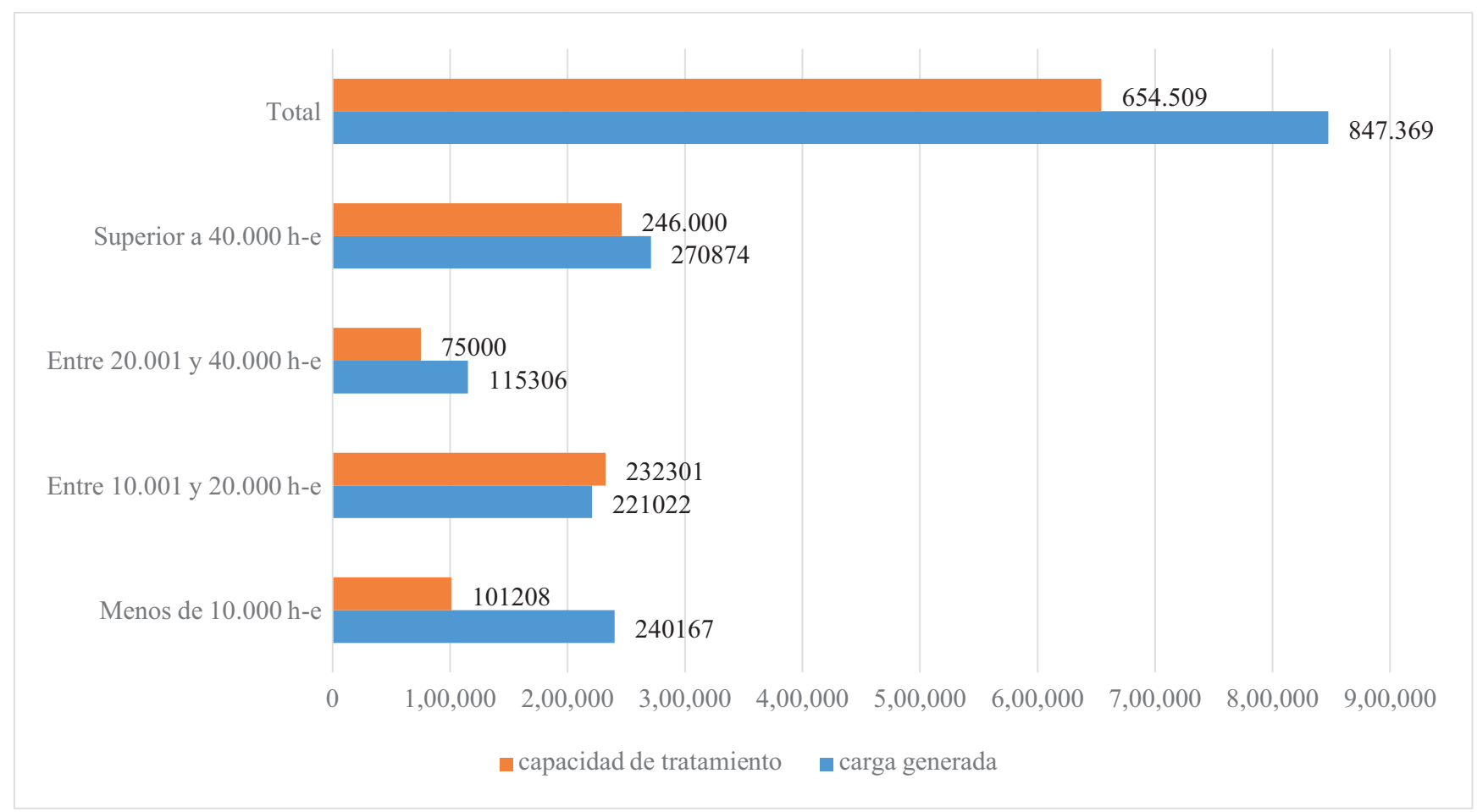

Fuente: EEA (2017).

Cuadro 1. Criterios de calidad de las aguas reutilizadas para el riego de cultivos leñosos

\begin{tabular}{|c|c|c|c|c|c|}
\hline \multirow[t]{2}{*}{ Uso del agua previsto } & \multicolumn{5}{|c|}{ Valor Máximo Admisible (VMA) } \\
\hline & $\begin{array}{l}\text { Nematodos } \\
\text { intestinales }\end{array}$ & Escherichia COLI & $\begin{array}{l}\text { Sólidos en } \\
\text { Suspensión }\end{array}$ & Turbidez & Otros criterios \\
\hline $\begin{array}{l}\text { Calidad } 2.3 \\
\text { a) Riego localizado de cultivos } \\
\text { leñosos que impida el contacto } \\
\text { del agua regenerada con los } \\
\text { frutos consumidos en la aliment- } \\
\text { ación humana }\end{array}$ & 1 Huevos/10 L & 10.000 UFC/ $100 \mathrm{~mL}$ & $35 \mathrm{mg} / \mathrm{L}$ & $\begin{array}{l}\text { No se fija } \\
\text { límite }\end{array}$ & $\begin{array}{l}\text { Otros contaminantes contenidos en la } \\
\text { autorización de vertido aguas residuales: se } \\
\text { deberá limitar la entrada de estos contami- } \\
\text { nantes al medio ambiente. En el caso de que } \\
\text { se trate de sustancias peligrosas deberá } \\
\text { asegurarse el respeto de las NCAs. Legionella } \\
\text { spp. } 100 \text { UFC }\end{array}$ \\
\hline
\end{tabular}

Fuente: Real Decreto 1620/2007 de 7 de diciembre, BOE núm. 294, de 08/12/2007.

que estos han mejorado su calidad, pero no son nuevos y como tal ya están contabilizados. De hecho, en el reparto de recursos utilizados por orígenes no se singularizan las aguas reutilizadas.

En el documento de seguimiento del Plan Hidrológico de Guadalquivir 2016-2017 publicado por la Confederación Hidrográfica ${ }^{27}$, el consumo referido a los distintos sistemas de explotación, se distribuye como se especifica en el Cuadro 2. El sistema identificado como "abastecimiento Jaén" concentra un 0,17 por 100 de la superficie regable, 1.444,90 ha, con una demanda de agua para uso agrario de $3,77 \mathrm{hm}^{3}$, un 0,13 por 100 del total, siendo nula el volumen reutilizado. Conviene tener presente, no obstante, que comunidades de

\footnotetext{
27. Consultar en https://www.chguadalquivir.es/documents/10182/12324 30/Informe_Seguimiento_del_Plan_Hidrologico_del_Guadalquivir_2016 _2017.pdf
}

regantes de la provincia localizadas en municipios de la Sierra de Cazorla, la Loma de Úbeda y Sierra Mágina se encuentran incluidas en el sistema de "Regulación General", con un volumen de reutilización de $16,45 \mathrm{hm}^{3}$. En el conjunto de sistemas de explotación de la CHG el agua reutilizada sólo representa un 0,57 por 100 del total, con un montante de $16,99 \mathrm{hm}^{3}$.

Entre 2011 y 2018 la Confederación Hidrográfica del Guadalquivir ha resuelto de forma favorable 4.077 expedientes, autorizando el uso de agua para riego en la provincia de Jaén. De ellos, sólo 7, un 0,17 por 100, son los que se refieren a la utilización de aguas tratadas, siendo minoría las comunidades de regantes que emplean este recurso. Es el caso, por ejemplo, de la Comunidad de Regantes de aguas residuales de Jaén, de la de la Dehesa-Menchón en Huelma, la de Beas de Segura y los Cuartos de las Albahacas, en Santo Tomé 
Cuadro 2. Consumo de agua para riego en la demarcación hidrográfica del Guadalquivir 2016/17 por sistemas de explotación

\begin{tabular}{|c|c|c|c|c|c|}
\hline & \multirow{2}{*}{$\begin{array}{l}\text { Superficie regable } \\
\text { На. }\end{array}$} & \multicolumn{4}{|c|}{ Uso agrario 2016-2017 $\left(\mathrm{hm}^{3}\right)$} \\
\hline & & Superficial & Subterránea & Reutilización & Total \\
\hline Guadalimar & $32.710,00$ & 15,86 & 127,66 & & 143,52 \\
\hline Abastecimiento Sevilla & 482,00 & 1,53 & 0,51 & & 2,04 \\
\hline Abastecimiento Córdoba & 167,00 & 0,00 & 0,37 & & 0,37 \\
\hline Abastecimiento Jaén & $1.444,00$ & 3,29 & 0,48 & & 3,77 \\
\hline Hoya de Guadix & $16.396,00$ & 66,37 & 15,74 & & 82,11 \\
\hline Alto Genil & $62.659,00$ & 104,60 & 78,86 & 0,53 & 183,99 \\
\hline Regulación General & $722.620,74$ & $1.841,49$ & 601,61 & 16,45 & $2.459,55$ \\
\hline \multirow[t]{2}{*}{ Bembézar-Retortillo } & $18.397,68$ & 76,51 & 5,39 & & 81,90 \\
\hline & $854.876,42$ & $2.109,65$ & 830,62 & 16,99 & $2.957,25$ \\
\hline
\end{tabular}

Fuente: Tomado de Confederación Hidrográfica del Guadalquivir, 2018.

y Cazorla. En la actualidad, existen más de una decena de expedientes abiertos de acuerdo con el Plan de aprovechamiento y distribución de la reserva de hasta $20 \mathrm{hm} 3$ de aguas regeneradas prevista en el Plan Hidrológico del Guadalquivir (artículo 19 de la normativa), entre los que se encuentran, el de la Comunidad de regantes Santa Ana en Torredelcampo, Camino de Begíjar-La Pilarica de Baeza, La Toya de Peal de Becerro, la C.R. Manuel López Pulido y cinco más en Martos, junto a las constituidas en Úbeda y Torredonjimeno con el mismo fin.

\section{Conclusiones}

A lo largo de las páginas precedentes se ha intentado clarificar y dar respuesta, con el análisis y la evidencia empírica disponible, a diferentes cuestiones relacionadas con el cumplimiento de la provincia de Jaén de los requisitos que establece la Directiva ARU sobre vertido y tratamiento de las aguas residuales urbanas. Además, se valora el uso que de este recurso se hace en la provincia por parte de la agricultura. Las principales conclusiones que se extraen del análisis realizado son las que se exponen a continuación.

El art. 4 de la Directiva ARU obliga a los estados miembros a depurar las aguas vertidas utilizando un tratamiento secundario o equivalente, a más tardar el 31 de diciembre del año 2000, para las aglomeraciones con una carga de más de 15.000 h-e y a más tardar el 31 de diciembre de 2005 para los vertidos en aguas dulces o estuarios que procedan de aglomeraciones con una cargar igual o superior a $2.000 \mathrm{~h}-\mathrm{e}$. En conjunto, la provincia presenta un bajo nivel de cumplimiento, inferior a la media nacional, regional y por debajo de los valores que registran otras provincias de la región como son Córdoba o Granada. En 2017, de las 64 depuradoras que debían estar funcionado en los municipios jiennenses con una carga estimada de vertido igual o superior a 2000 h-e sólo lo hacen 33, un 51,6 por 100. En conjunto, la población servida por las instalaciones activas representaba un 67 por 100 del total.

La provincia jiennense mantiene un importante déficit en capacidad de depuración. Veintisiete años después de la aprobación de la Directiva ARU, $31 \mathrm{mu}-$ nicipios con una carga de vertido estimada igual o superior a 2.000 h-e no depuran, bien porque la EDAR de la que disponen está parada o simplemente no cuentan con esta infraestructura. Especialmente grave resulta el hecho de que tres localidades, Martos Úbeda y Torredonjimeno, con una carga de vertido superior a $15.000 \mathrm{~h}$-e, que tienen la obligación de tratar las aguas residuales desde el 1 de enero de 2001, en 2018 seguían vertiendo al cauce sin depurar. Además, 22 pueblos, con un volumen de vertido entre 7.000 y 10.000 h-e, entre los que se incluyen Valdepeñas de Jaén, Campillo de Arenas, Satisteban del Puerto, Sabiote, Castillo de Locubín, Vilches, Navas de San Juan o La PuertaPuente Génave no cuentan con una EDAR. Esta realidad determina el grado de contaminación de las masas de agua, repercutiendo muy desfavorablemente en las condiciones del medio natural hídrico provincial.

El fomento de la reutilización de las aguas regeneradas se ha incorporado a la legislación nacional y autonómica que regula el uso de los recursos hídricos como un objetivo clave, impulsado desde la UE. Ante todo, se trata de favorecer la protección a largo plazo del medio 
natural hídrico y aumentar la oferta disponible de agua para atender una demanda creciente. En la actualidad, sin embargo, el volumen de agua reutilizada es muy escaso, menos de un 0,8 por 100 en el conjunto de la demarcación hidrográfica del Guadalquivir, en la que se incluye el 95 por 100 de la superficie de la provincia de Jaén. En línea con lo expuesto, resulta que en la provincia no existe ninguna estación de regeneración de aguas depuradas, siendo menos de una decena las comunidades de regantes localizadas en municipios de la provincia que emplean aguas depuradas en una EDAR.

La importancia del servicio de depuración de las aguas vertidas para el medio natural, la disponibilidad de recursos hídricos complementarios y en buenas condiciones para el riego de los campos de cultivo y, a medio y largo plazo, la salud de la población exige que las autoridades locales, provinciales y regionales realicen una apuesta firme por el desarrollo y mejora de los sistemas de tratamiento de las aguas residuales urbanas en todos los municipios jiennenses.

Los ciudadanos deben ser consciente de que no se trata exclusivamente de cumplir con los requisitos que establece la legislación europea sobre protección de los recursos hídricos, para evitar multas que pudieran sancionar el vertido de aguas contaminantes, tanto por parte de la Confederación Hidrográfica del Guadalquivir, como de la Comisión Europea, tal y como ha ocurrido a nivel nacional. Ante todo, urge establecer objetivos, diseñar estrategias y poner en marcha actuaciones dirigidas a mejorar la calidad de los vertidos de aguas residuales, poner en valor este recurso y reutilizar las aguas tratadas, lo que contribuirá a mejorar la calidad y cantidad de los recursos hídricos disponibles en la provincia.

\section{BIBLIOGRAFÍA}

AEAS 2017: Informe sobre Aguas Residuales en España. Asociación Española de Abastecimiento de Agua y Saneamiento. Madrid, AEAS.

Alianza por el Agua 2003: Manual de depuración de aguas residuales urbanas. http://alianzaporelagua.org/documentos/MONOGRAFIC03.pdf. Consulta realizada el 15 de julio de 2018.

Araque Jiménez, E., Gallego Simón, V., J. y Sánchez Martínez, J. D. 2002: "El olivar regado en la provincia de Jaén", Investigaciones Geográficas, 28, 5-32. https://doi.org/10.14198/ INGEO2002.28.03

Ayuntamiento de Jaén 2013: Plan General de Ordenación Urbanística. V Estudio de impacto ambiental. El ciclo integral del agua. Jaén, Ayuntamiento de Jaén.
Berbel, J., Expósito, A. 2006: "Análisis del coste del servicio de abastecimiento urbano de agua en la Demarcación del Guadalquivir", Revista de Estudios Regionales, 76, 161-183. I.S.S.N.: 0213-7585 (2006).

Collins, R., Kristensen, P., Thyssen, N. 2009: Water Resources across Europe-Confronting Water Scarcity and Drought. European Environmental Agency (EEA Report series. N. 2/2009), Copenhage, Dinamarca.

Comisión Europea 2012: Comunicación de la comisión al parlamento europeo, al Consejo, al Comité Económico y Social Europeo y al Comité de las Regiones. Plan para salvaguardar los Recursos Hídricos de Europa. Bruselas, Bélgica.

Comisión Europea 2017a: Terms and Definitions of the Urban Waste Water Treatment Directive 91/271/EEC. Consultado en http://ec.europa.eu/environment/water/water-urbanwaste/ info/pdf/terms.pdf. Consultado el 9 de mayo de 2018.

Comisión Europea 2017b: Informe de la Comisión al Parlamento Europeo, al Consejo, al Comité Económico y Social Europeo y al Comité de las Regiones. Noveno informe sobre el estado de ejecución y los programas para la aplicación (conforme al artículo 17) de la Directiva 91/271/CEE del Consejo sobre el tratamiento de las aguas residuales urbanas, https://eur-lex.europa.eu/legal-content/ES/TXT/PDF/ ?uri=CELEX:52017DC0749\&from=ES. Consultado el 10 de mayo de 2018.

Diputación Provincial de Jaén 2003: Ciclo integral del agua. Abastecimiento, tratamiento y distribución de agua potable; consumo de agua potable; red de alcantarillado y depuración de aguas, Jaén, Diputación Provincial de Jaén.

EEA 2017: Data and Maps, https://www.eea.europa.eu/es. Consultado el 11 de mayo de 2018.

Expósito, A. Berbel, J. 2017: "Why is water pricing ineffective for deficit irrigation schemes? A case study in southern Spain", Water Resources Management INE, 2018. Indicadores sobre el agua, http://www.ine.es/jaxi/Tabla.htm? path=/t26/p069/p0 3/serie/I0/\&file=01001.px\&L=0. Consultado el 23 de abril de 2018.

Gallego Valero, L., Moral Pajares, E., y Román Sánchez, I. 2018: "The tax burden on wastewater and the protection of water ecosystems in EU countries", Sustainability, 10 (1), 212. https://doi.org/10.3390/su10010212

Gallego-Valero, L., Moral-Pajares, E., y Román-Sánchez, I. M. 2019: "Crop production and irrigation: deciding factors of wastewater reuse in Spain?", Desalination and Water Treatment, 150, 91-98. https://doi.org/10.5004/dwt.2019.23618

Garcia, X., Pargament, D. 2015: "Reusing wastewater to cope with water scarcity: economic, social and environmental considerations for decision-making", Resources, Conservation and Recycling, 101, 154-166. https://doi.org/10.1016/j.resconrec.2015.05.015 
Gharbia, S. S., Aish, A., Abushbak, T., Qishawi, G.; Al-Shawa, I., Gharbia, A. y Pilla, F. 2016: "Evaluation of wastewater post-treatment options for reuse purposes in the agricultural sector under rural development conditions", Journal of Water Process Engineering, 9, 111-122. https://doi.org/10.1016/j. jwpe.2015.12.003

Hochstrat, R.; Wintgens, T.; Kazner, C.; Jeffrey, P.; Jefferson, B.; Melin, T. 2010: "Managed aquifer recharge with reclaimed water: approaches to a European guidance framework", Water Science and Technology, 62 (6), 1265-1273. https://doi. org/10.2166/wst.2010.386

INE, 2018. Indicadores sobre el agua, http://www.ine.es/jaxi/Tabla.htm?path=/t26/p069/p03/serie/l0/\&file=01001.px\&L=0. Consultado el 23 de abril de 2018.

Kalavrouziotis, I.K., Kookkinos, P., Oron, G., Fatone, F., Bolzonella, D., Vatyliotou, M., et al., 2013: "Current status in wastewater treatment, reuse and research in some Mediterranean countries", Desalination and Water Treatment, 53 (8), 2015-2030. https://doi.org/10.1080/19443994.2013.860632

Lazarova V., Levine, B., Sack, J., Cirelli, G., Jeffrey, P., Muntau, H., y Brissaud, F. 2001: "Role of water reuse for enhancing integrated water management in Europe and Mediterranean countries", Water Science and Technology, 43 (10), 25-33. https://doi.org/10.2166/wst.2001.0571

Llamas, R. L., Aldaya, M., Garrido, A., y López, E. 2009: "Soluciones para la escasez del agua en España y su aplicación a otras regiones", Revista de la Real Academia de Ciencias Exactas, Físicas y Naturales, 103 (1), 41-54. ISSN 1137-2141.

Melgarejo, J. 2009: "Efectos ambientales y económicos de la reutilización del agua en España”, Clm.Economía, 15, 245-270.

Melgarejo, J., y López-Ortiz, M. I. 2016: "Depuración y reutilización de aguas en España”, Agua y Territorio, 8, 22-35. https://doi.org/10.17561/at.v0i8.3293

Melian-Navarro, A. M., y Fernández-Zamudio, M. A. 2016 "Reutilización de agua para la agricultura y el medioambiente", Agua y Territorio, (8), 80-92. https://doi.org/10.17561/ at.v0i8.3298

Miller, G. W. 2006: "Integrated concepts in water reuse: managing global water needs", Desalination, 187 (1), 65-75. https:// doi.org/10.1016/j.desal.2005.04.068

Ministerio de Agricultura, Pesca y Alimentación 2018: Categorías y tipos de masas de agua, http://www. mapama.gob.es/ es/agua/temas/estado-y-calidad-de-las-aguas/aguas-superficiales/categorias-y-tipos-de-masas-de-agua/- Consultado el 24 de enero de 2019.

Ministerio de Agricultura, Pesca y Alimentación 2018b: Espacios naturales protegidos en España, https://www. mapama. gob.es/es/biodiversidad/temas/espacios-protegidos/espacios-naturales-protegidos/default.aspx. Consultado el 1 de febrero de 2019.
Ministerio de Agricultura, Pesca y Alimentación 2019: Encuesta sobre superficies y rendimientos de cultivos, https://www.mapa.gob.es/es/estadistica/temas/estadisticas-agrarias/agricultura/esyrce/. Consultado el 1 de febrero de 2019.

Molinos-Senante, M., Hernández-Sancho, F., Sala-Garrido, R. 2010: "Economic feasibility study for wastewater treatment: A cost-benefit analysis", Science of the Total Environment, 408, 4396-4402. https://doi.org/10.1016/j.scitotenv.2010.07.014

Pedrero, F., Kalavrouziotis, I., Alarcón, J. J., Koukoulakis, P. y Asano, T. 2010: "Use of treated municipal wastewater in irrigated agriculture-Review of some practices in Spain and Greece", Agricultural Water Management, 97 (9), 1233-1241. https://doi.org/10.1016/j.agwat.2010.03.003

Pedro-Monzonís, M., Solera, A., Ferrer, J., Estrela, T., Paredes-Arquiola, J. A. 2015: "Review of water scarcity and drought indexes in water resources planning and management", Journal of Hydrology, 2015, 527, 482-493. https://doi. org/10.1016/j.jhydrol.2015.05.003

Ruiz-Rosa, I., García-Rodríguez, F. J. y Mendoza-Jiménez, J. 2016: "Development and application of a cost management model for wastewater treatment and reuse processes", Journal of Cleaner Production, 113, 299-310. https://doi. org/10.1016/j.jclepro.2015.12.044

Sánchez, J. D. y Ortega, A. 2016: "El monocultivo olivarero jiennense: conformación histórica, valores patrimoniales y proyección cultural-turística", Cuadernos de Turismo, 37, 377 402. ISSN 1139-7861.

Sánchez, J. D., Gallego, V. J. G. y Araque, E. 2011: "El olivar andaluz y sus transformaciones recientes", Estudios Geográficos, 72 (270), 203-229. https://doi.org/10.3989/estgeogr.2 01109

Schewe, J., Heinke, J., Gerten, D., Haddelandc, I., Arnelld, N.W., Clarke, D.B., Dankersf, R., Eisnerg, S., Feketeh, B.M., Colón-Gonzálezi, F.J. 2014: "Multimodel assessment of water scarcity under climate change", Proc. Natl. Acad. Sci., 111, 3245-3250. https://doi.org/10.1073/pnas.1222460110 UN Water 2017: Informe Mundial de las Naciones Unidas sobre el Desarrollo de los Recursos Hídricos 2017. Aguas residuales: el recurso desaprovechado. UN, París.

Wilcox, J., Nasiri, F., Bell, S., Rahaman, M. S. 2016: "Urban water reuse: A triple bottom line assessment framework and review", Sustainable Cities and Society, 27, 448-456. https:// doi.org/10.1016/j.scs.2016.06.021

Winpenny, J., Heinz, I., y Koo-Oshima, S. 2013: "Reutilización del agua en la agricultura: ¿Beneficios para todos?", Informe sobre temas hídricos de la FAO, 35.

World Resources Institute 2007: https://www.wri.org/ Consultado el 1 de febrero de 2019. 